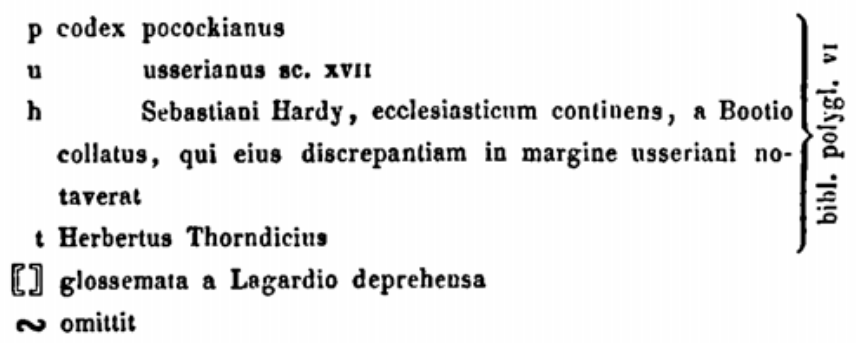

Versunm numeri iidem sunt qui in Grabii editione, repetita Tiguri anno 1730. sed qui Breitingeri curas laudat, vereor ut unquam exemplar tigurinum legerit. in apocryphis certe negligentissime editum inveni.

\title{
Ecclesiasticus
}

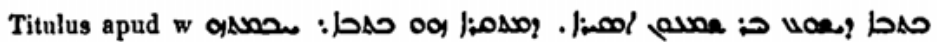

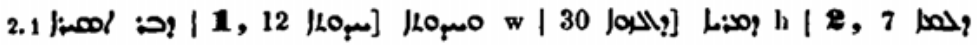

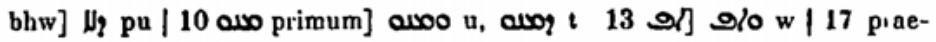
mittuntur huic versui apud w octo vocabula, a nobis e fide $b$ in fine versus

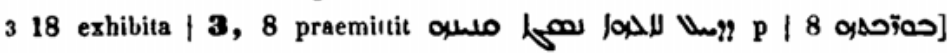

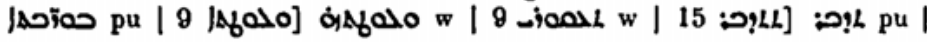

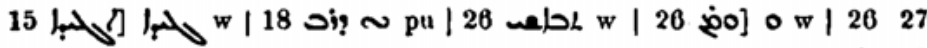
4 quae post oflict ante et

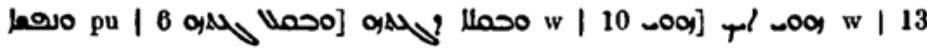

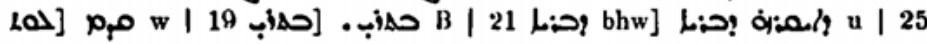

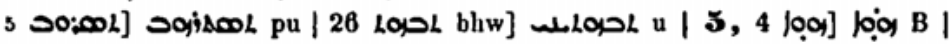

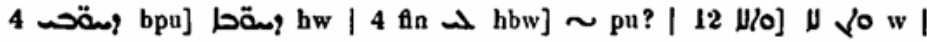

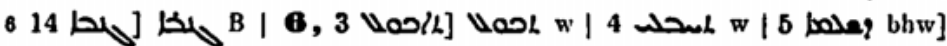

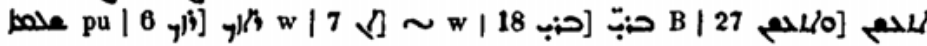

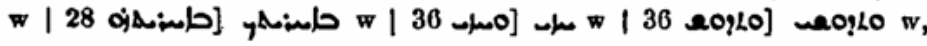

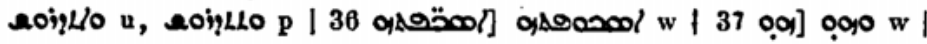

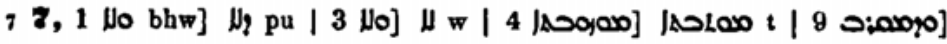
| 9.10 sunt unus versus nonus apud w, ad hunc adscribit t

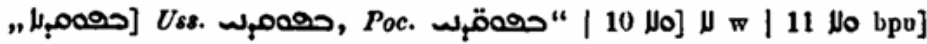

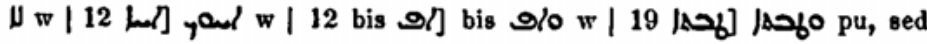

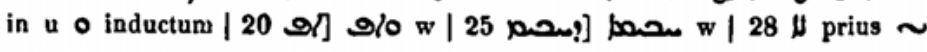

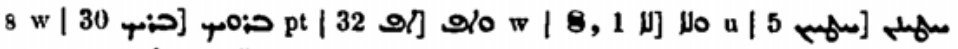

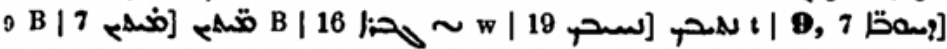
!nنصا $t$, videtur enim lig paginam significare in illis quae ad Ezdr. 5, 14

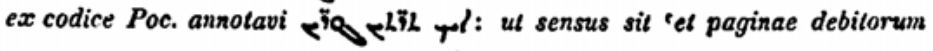


inscribaris', in libro nempe accepti et expensi: neque enin de adulterio sermo esse potest, quia de meretrice institutus est "

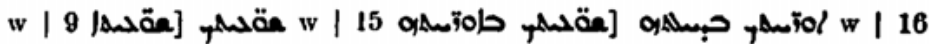

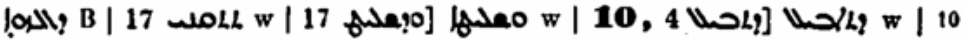

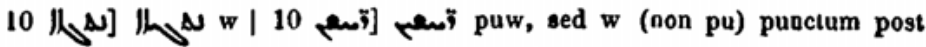

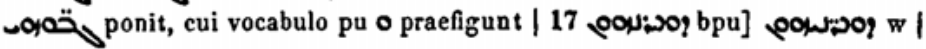

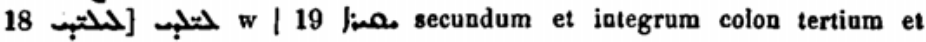
quartum $\sim \mathrm{u}$, colon primum et quartum $\sim \mathrm{h}$ | 19 wilg bis] uil/ $\mathrm{p}$ bis

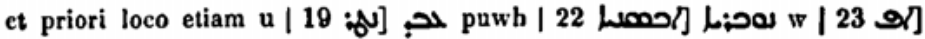

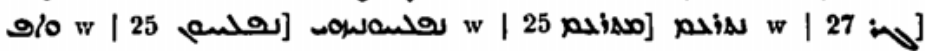

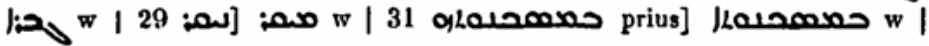

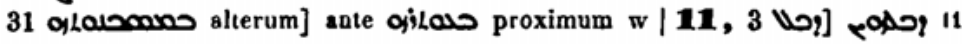

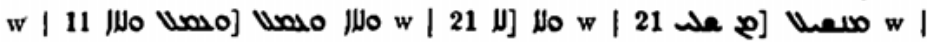
27 t sic: ", $/ \mathrm{Na}$ ] sic et nostri: verum ex gr. coniectura est, scribendum حسم

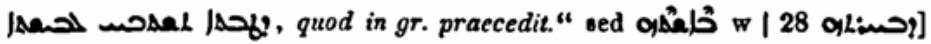

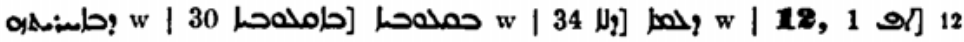

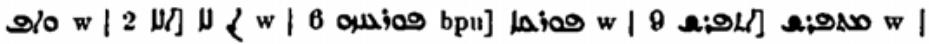

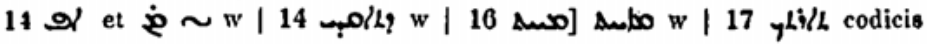
festinatione typographi remansit, scribe 13 |

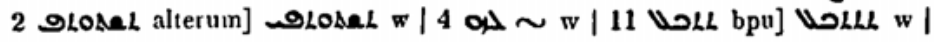

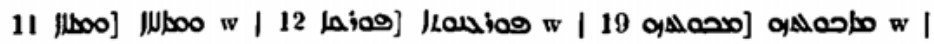

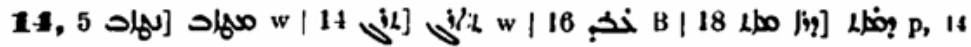

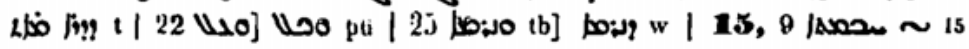

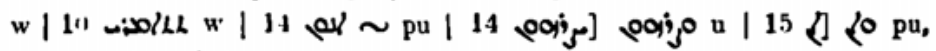
|

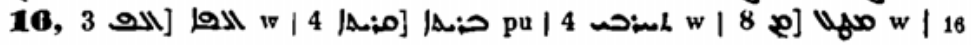

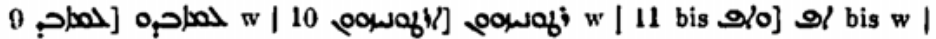

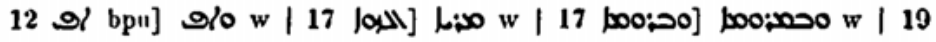

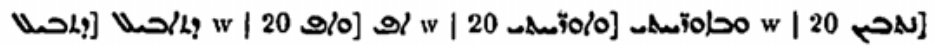

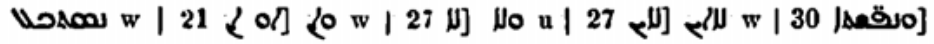

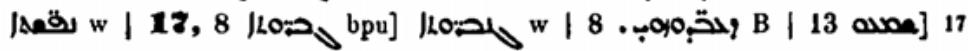

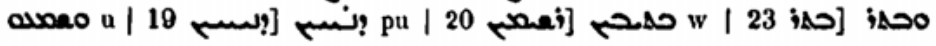

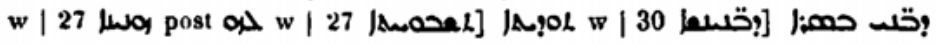

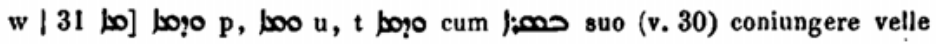

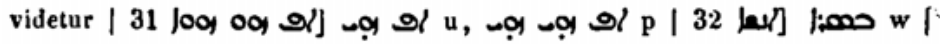

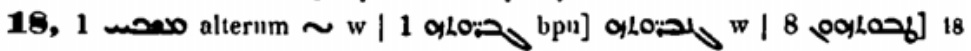

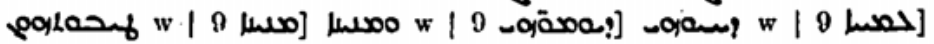




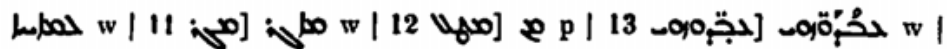

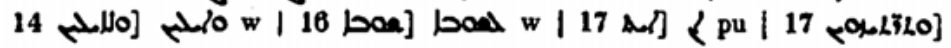

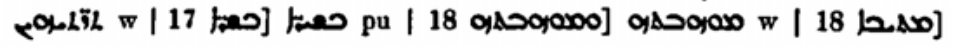

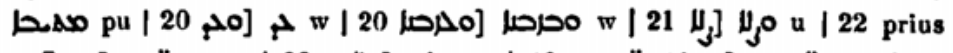

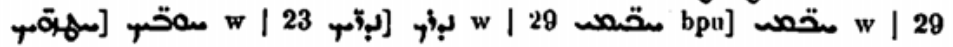

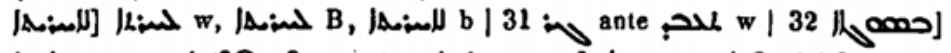

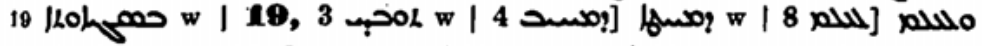

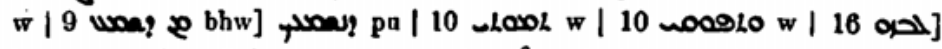

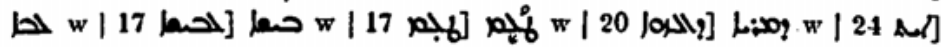

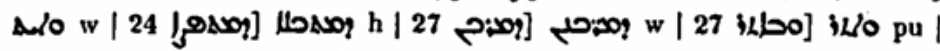

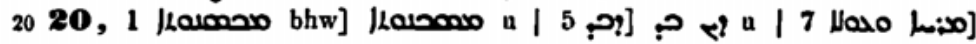

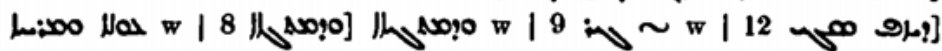

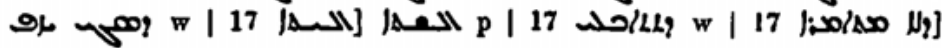
|

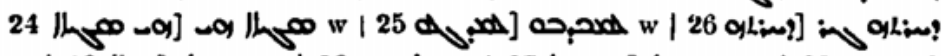

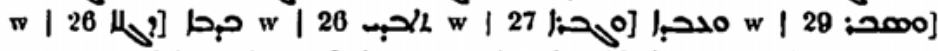

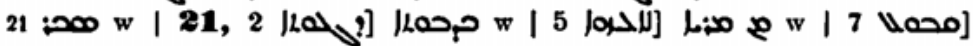

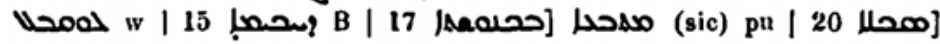

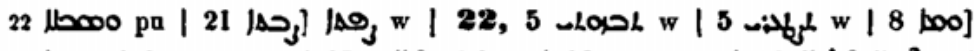

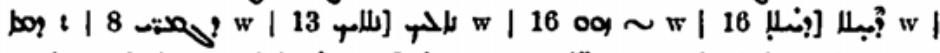

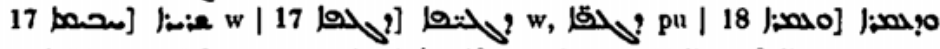

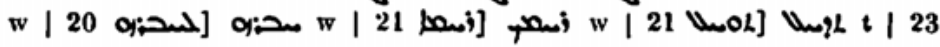

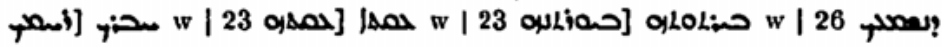

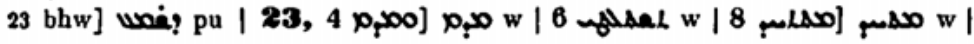

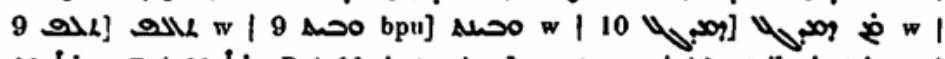

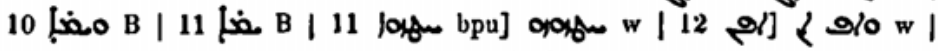

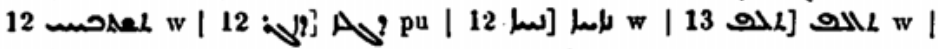

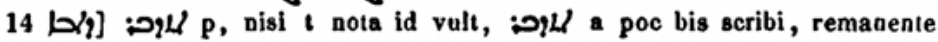

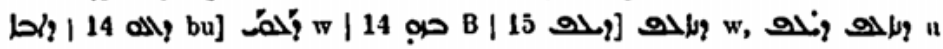

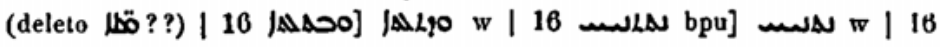

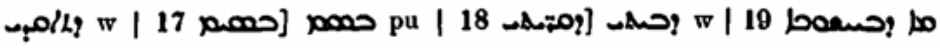
bpu]

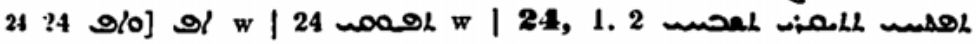

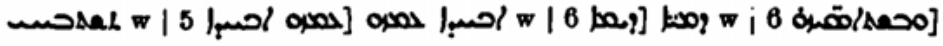

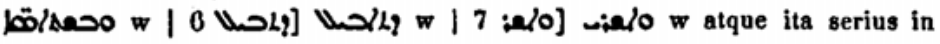

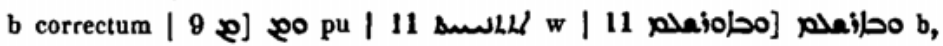

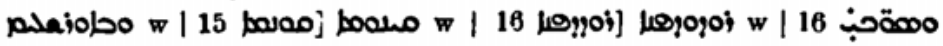

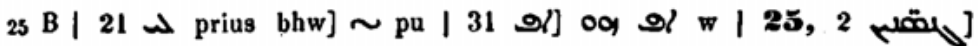

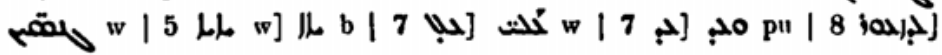




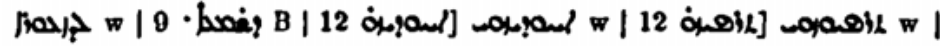

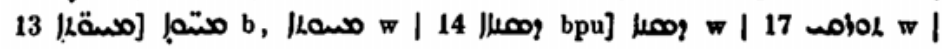

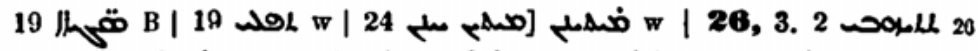
| 20

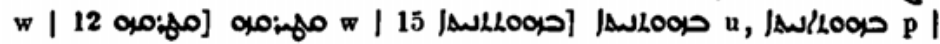
[حمدم 18 | 18 addunt |

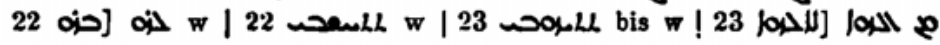

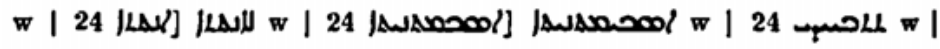
28 | w | 1 | 1 | 26.26 | (ante v8 27) alterum] praenittit

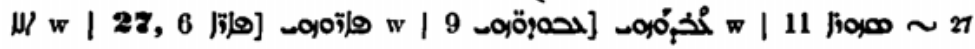

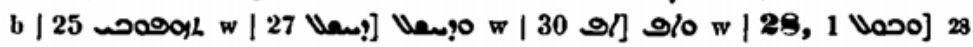

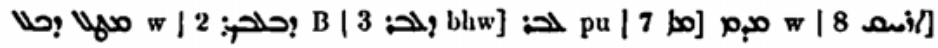

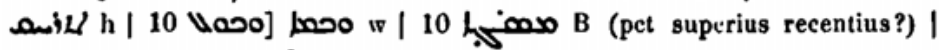

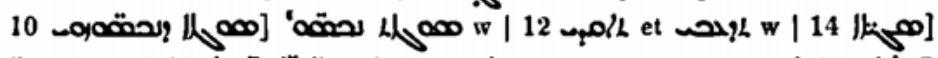

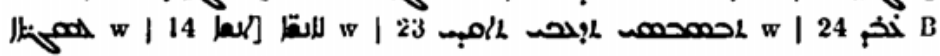

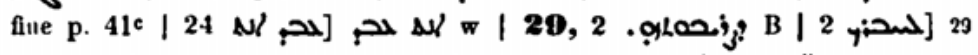

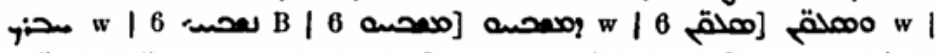

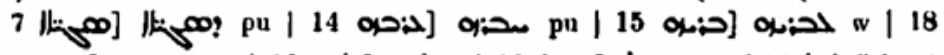

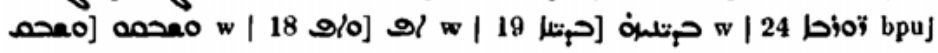

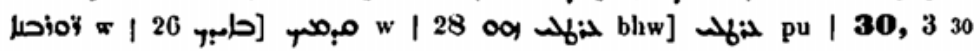

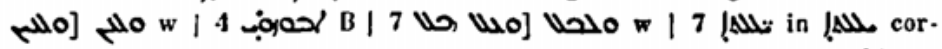

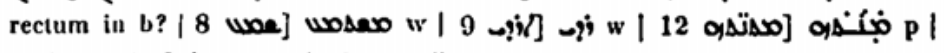

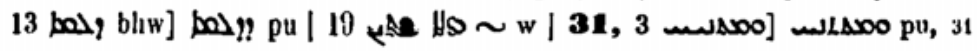

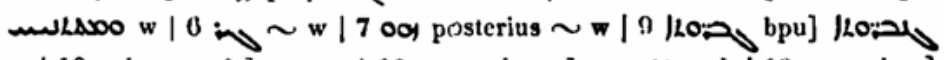

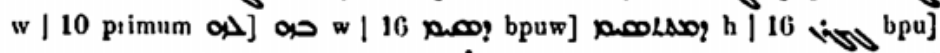

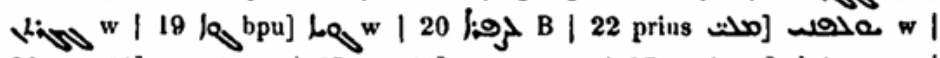

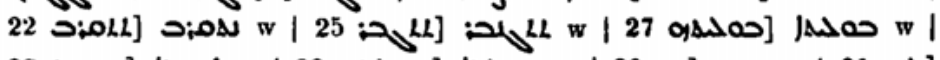

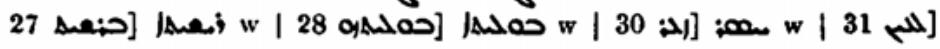

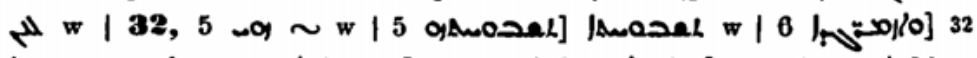

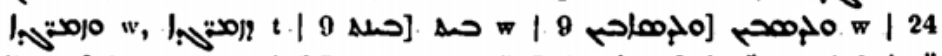

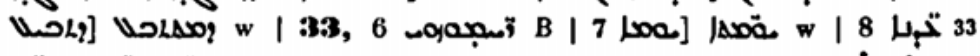
منفمدا 20 |

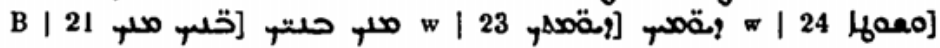

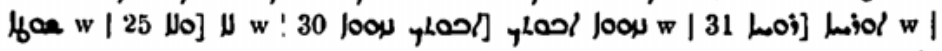

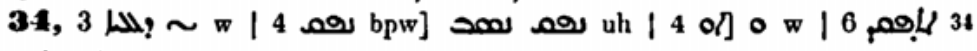

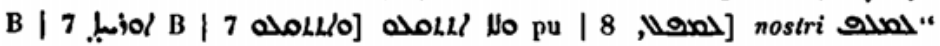
Thorndice, quod non intelligo | 


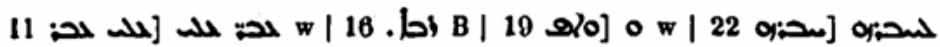

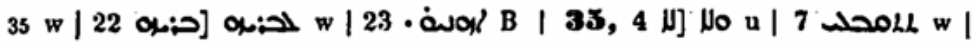

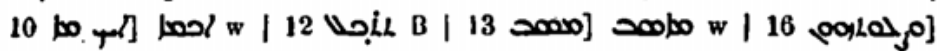

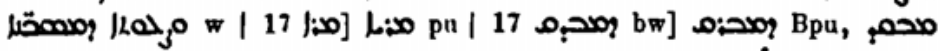

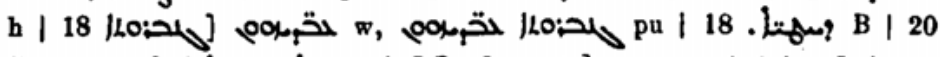

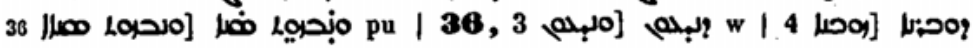

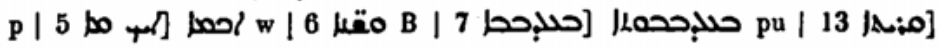

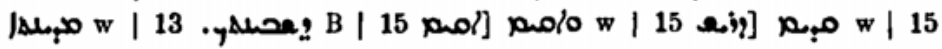
| 1

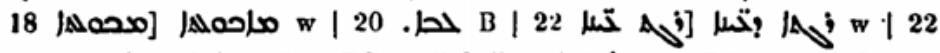

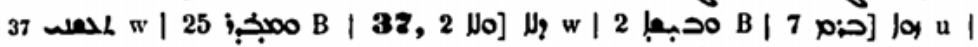

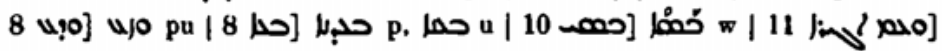

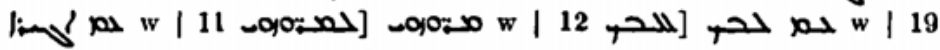

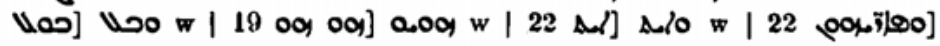

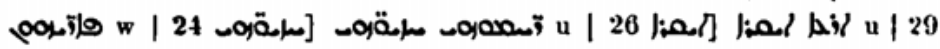
3) |

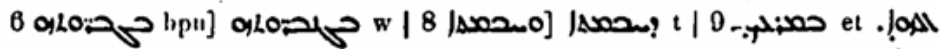

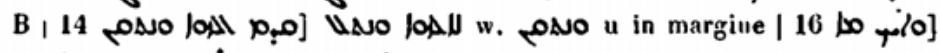

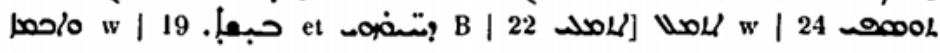

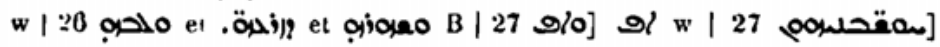

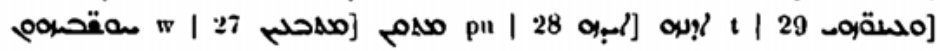

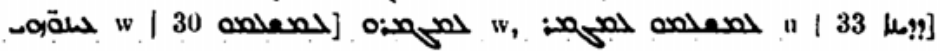

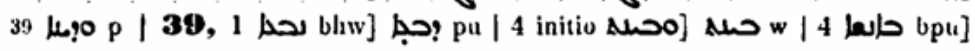

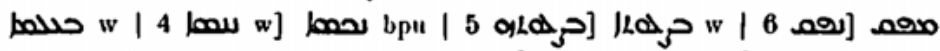
w

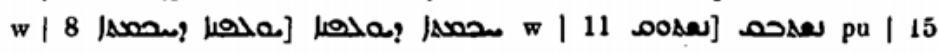

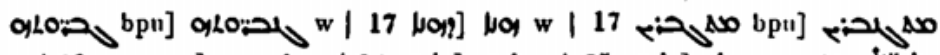

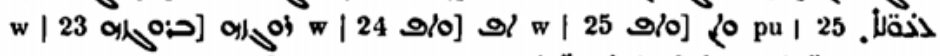

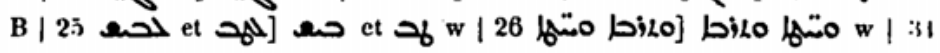

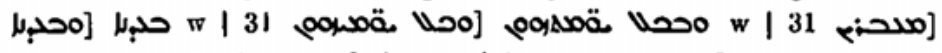

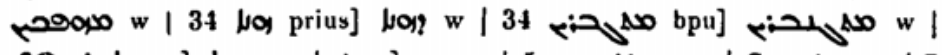

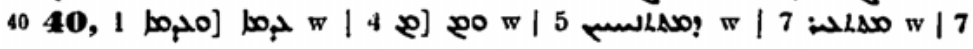

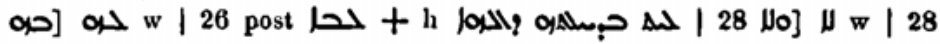

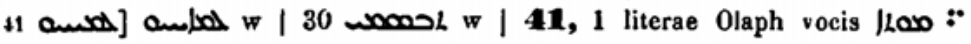

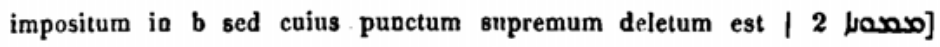

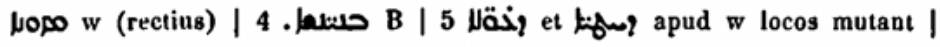

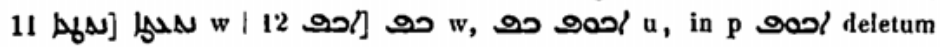

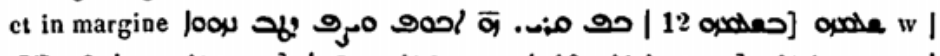
4242,9 | 


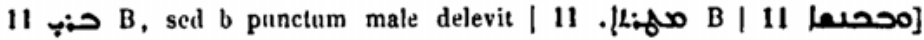

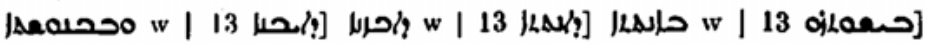

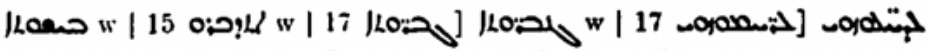

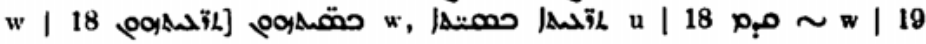
|

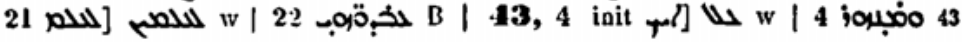

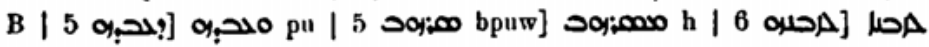

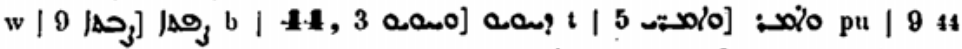

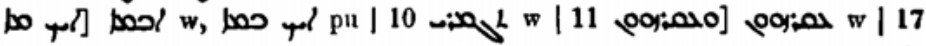

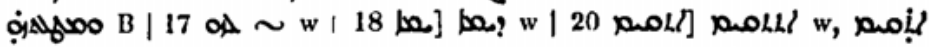

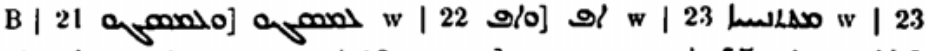

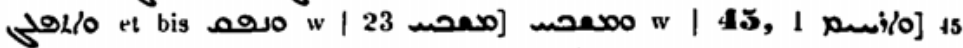

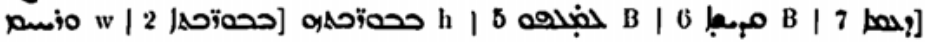

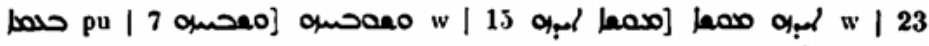
post

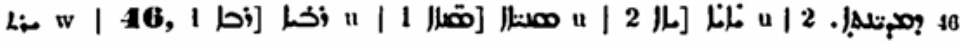

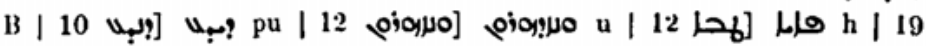

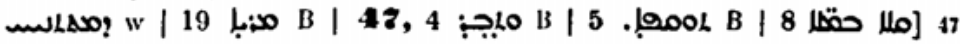
|

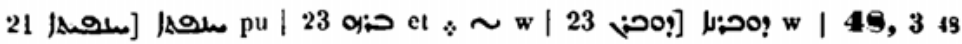

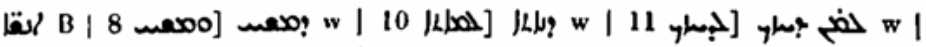

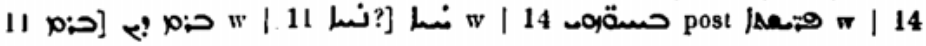

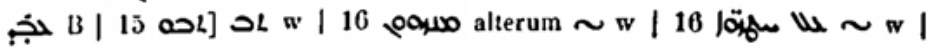

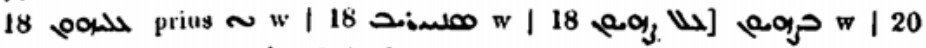
[/0]

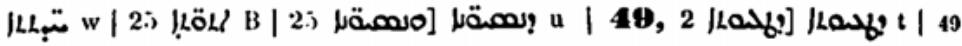

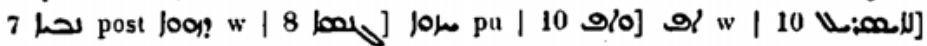

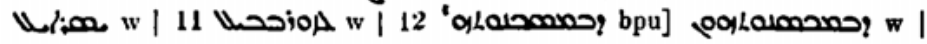
1. 16

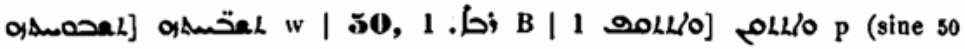

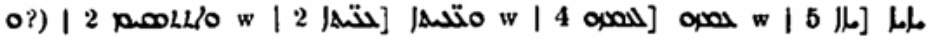

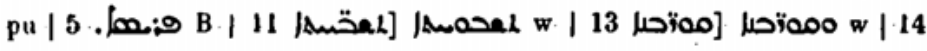

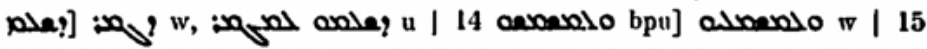

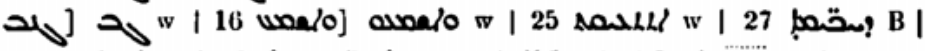

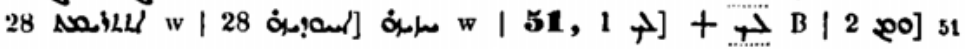

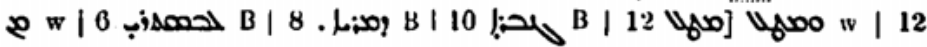

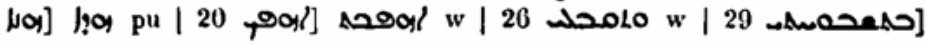

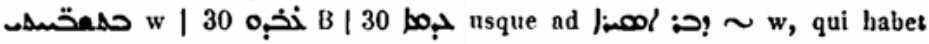

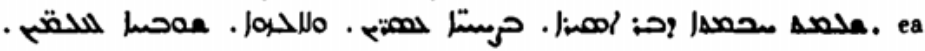


quae inter 2 et

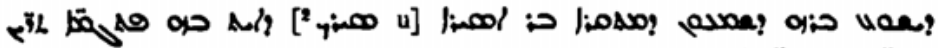
الهق مسمقمار .

\section{Sapientia Salomonis}

Tilulus apud w: : 001

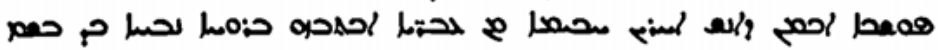
.

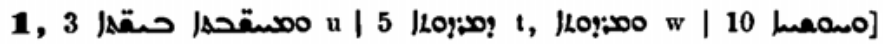

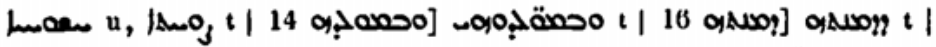

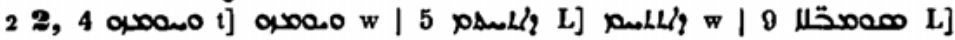

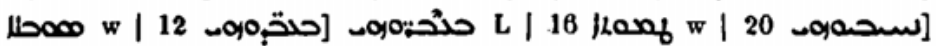

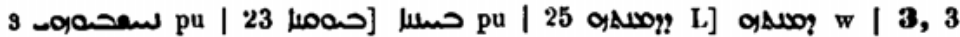

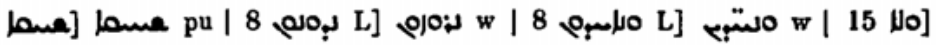

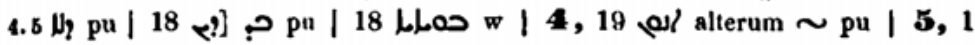

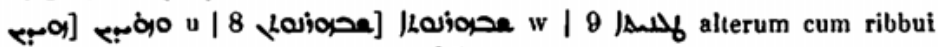

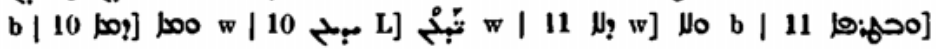

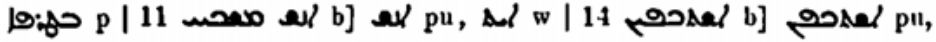

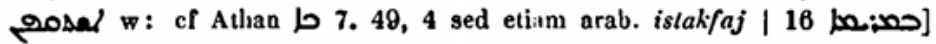

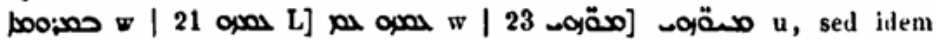

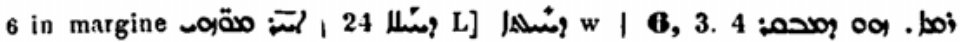

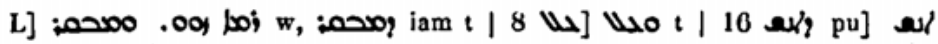

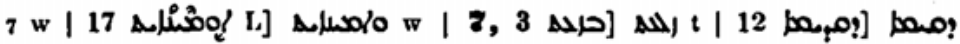

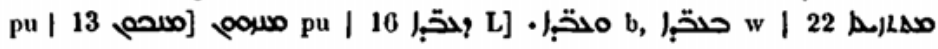

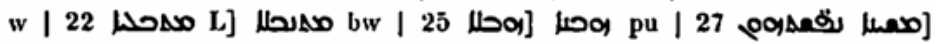

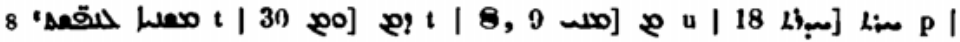

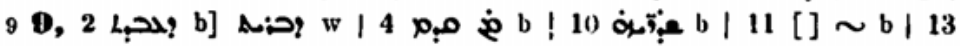

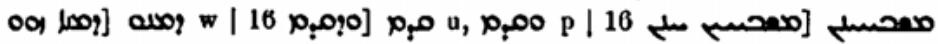

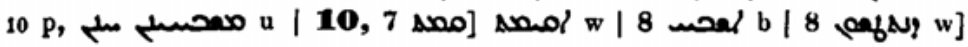

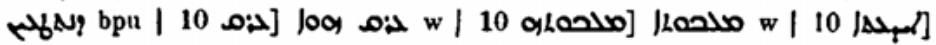

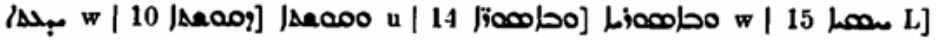
|

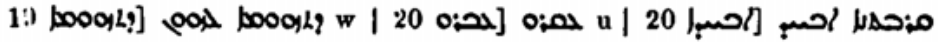

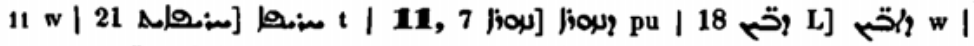

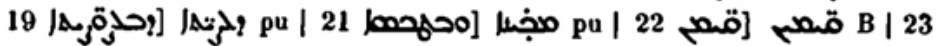

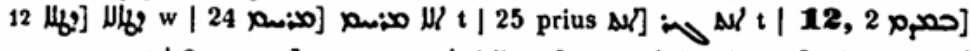

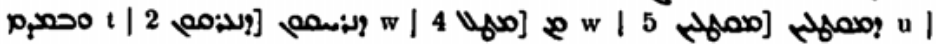

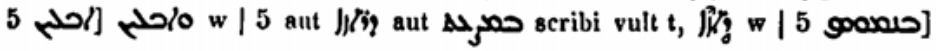

